\title{
Bacteriological Findings Within Internal Implant Hole Following Flapless Implant Placement
}

\author{
Khudair Ali Abd, B.D.S., H.D.D. (1) \\ Basima GH. Ali, B.D.S., M.Sc. ${ }^{(2)}$ \\ Abbas S.AL-Mizraqchi, M.Sc., Ph.D. ${ }^{(3)}$
}

\begin{abstract}
Back ground: Microbial penetration inside the implant's internal hole creates a bacterial reservoir that is related with an area of inflamed connective tissue opposite the fixture-abutment junction and this can affect the health of the peri-implant tissue.

Aims of the study: Evaluate the types aerobic and anaerobic bacterial count-percentage and difference between Aerobic and Anaerobic microflora in the implant screw hole three months after implant placement. Monitor the periodontal health status of all patients, throughout the study.

Material and methods: Study methodology; Eight partially edentulous patients received 20 dental implants and these implants done with flapless surgical procedure. All patients examined clinically to determined their oral health status by examination of their plaque index, Gingival index and Bleeding on probing, each two weeks for 90 days (8visits) throughout the study period. Three months after that, the plaque sample collected from the internal hole of fixture and transfer to bacterial investigation and assessment the amount of anaerobic and aerobic bacteria.

Results: Although the anaerobic viable count is higher than that of aerobic, but with statistically not significant difference between those counts ( $P>0.05)$.

Keywords: screw hole, flapless surgical implant placement, bacterial count, Aerobic and Anaerobic bacteria. (J Bagh Coll Dentistry 2018; 30(3): 13-16)
\end{abstract}

\section{INTRODUCTION}

Studies of dental implants over the years have showed great dependability for the success rates of implant treatment ${ }^{(1)}$. Longstanding implant success is highly dependent on adaptation of the implant with oral soft and hard tissues. Commonly, the crestal bone at the implant-tissue interface is the early point of surgical trauma and tissue breakdown.

At this instant there is no single flap design that functions as the main approach for all single implant surgery, and as the need for esthetics practices rises with a little aggressive system, so, extremely, confirms the instability in flap design (2).

Implant dentistry is not an easy work, but it responsible for obtaining best esthetic, function and phonetic outcomes, also responsible for increasing the stability of alveolar bone with the peri-implant soft tissues. ${ }^{(3)}$

In deference to the several factors that cause failure of dental implants for example bone condition, occlusion and so on, numerous studies supported that microbial infections could have serious consequences lead to failure in dental implants prosthesis. For most implant systems, micro leakage in dental implants may cause mucositis within a short extent from the alveolar bone crest. ${ }^{(4)}$

Infiltration of bacteria in the implant's internal screw cavity forms a reservoir of bacterial flora

(1) Ministry of health, Baghdad, Iraq.

(2) Professor, Department of Periodontics, College of Dentistry, University of Baghdad.

(3) Professor, Department of Microbiology, College of Dentistry, University of Baghdad. that is associated with an area of connective tissue inflammation opposing the abutment- fixture connection and this can influence with the periimplant tissue health ${ }^{(5)}$.

Microorganisms colonizing surfaces are progressively developed into complex biofilms. Species within the biofilm interrelate specially with each other. Such as, initial colonists, for example Actinomyces or Streptococcus species, are necessary for the adhesion of late -colonizing gram-negative species. A sufficient cooperative maintenance care for patients with dental implants has an essential function in attaining longstanding success for implant-supported restorations ${ }^{(6)}$.

\section{MATERIALS \& METHODS \\ Study Sample}

The sample included patients who attended the Dental Unit/Department of Oral and Maxillofacial Surgery in the Teaching Hospital of College of Dentistry- University of Baghdad for the purpose of implant placement.

A total of 20 dental implants(DIs) in 8 Iraqi patients, 4 males and 4 females, age ranged from 30 to 45 years that fulfilled the inclusion criteria were recruited for this study.

Inclusion criteria:

1- Patient who were partially edentulous (patients requiring at least two teeth replacement in the anterior, premolar and posterior region).

2- Systemically healthy

3- Free of active caries and active periodontitis

4- Smokers: patients smoke less than 10 cigarettes per day (light smokers). ${ }^{(7)}$ 
5- Patients who were well motivated for implant treatment and maintaining good oral hygiene and follow a regular periodontal maintenance protocol.

\section{Exclusion criteria}

1- Edentulism.

2- Medically compromised patients such as uncontrolled diabetes, bleeding disorders, osteoporosis; patients on radiation therapy; immunocompromised states and any disease affecting on bone healing.

3- Active periodontitis and chronic periodontitis with pocket more than $4 \mathrm{~mm}$ and need current periodontitis treatment.

4- Smokers: patients regularly smoked at least 10 cigarettes on average per day, for the last five years.

5- Any medications that compromise or effect on the healing process of bone like corticosteroids.

6- Chronic Alcoholism.

7- History and clinical evidence of parafunctional habits (Bruxism, clenching).

8- Tumor or metastatic disease.

9- Allergy to chlorhexidine gluconate

10-Patient taken antibiotic prior to culture at the $2^{\text {nd }}$ stage of implant for at least 15 days or 1 month.

11-Pregnant women.

\section{Clinical examination:}

1- Extraoral examination

2- Intraoral examination

3- Before surgery and at each visit patient's motivation and oral hygiene instruction as well as scaling were repeated

4- Clinical periodontal parameters examination done every 2 weeks for 4 months ( 8 visits) for all patients include:

-Assessment of plaque index (PLI) ${ }^{(8)}$

-Assessment of gingival index (GI) ${ }^{(9)}$

-Assessment of bleeding on probing (BOP) ${ }^{(10)}$

5- Radiographic examination: A pre-operative orthopantomography (OPG) was obtained for all patients in Almaghreb Specialized Dental Center for radiographic examinations.

\section{Surgical procedure}

Before surgery, patients were instructed to rinse with $0.12 \% \mathrm{CHX}$ solution for $1 \mathrm{~min}$. as part of the standard surgical protocol and the skin was scrubbed with povidone-iodine solution as antiseptic agent.

The surgical site was anesthetized and implants were placed in site previously examined and according to a studied treatment plane in respect to the demand of the patients. Flapless surgical design was selected.

Before placement of the healing abutment, all implant screw holes were rinsed with about $20 \mathrm{ml}$ of sterile saline solution by disposable syringe and dried using surgical suction, thus preventing further contamination of the screw hole with saliva or blood.

The healing abutments were then screwed into place by hex driver with the same torqueing protocol for all flapless implant.

\section{Bacteriological Examination:}

1-Preparation of the following media:

- Phosphate buffer saline (PBS)

- Culture media preparation: Brain Heart Infusion Agar (BHI)

- Mannitol Salt Agar

2-Specimen Collection: Plaque samples were collected from the internal screw holes under standard condition, approximately 3 months after surgical placement using sterile micro brush and then the brushes immediately dropped into screwed universal tube containing PBS.

3-Culturing technique: The collected sample were mixed using Vortex mixer (Griffin and George LTd. England) for 2-3 minutes. Tenfold steps of serial dilutions were prepared using sterile phosphate buffer saline. From each dilution $\left(10^{-}\right.$ $\left.3,10^{-5}\right), 0.1 \mathrm{ml}$ was withdrawn and then, inoculate in to the petri dishes contain BHI Blood Agar media, and spread by using sterile microbiological spreader on the plates of BHIBlood agar. (11) Then incubate aerobically and anaerobically.

4-Enumeration of bacterial colonies (count)colony forming unit per one mil liter $(\mathrm{CFU} \mathrm{ml})$ : Identification of most common bacterial colonies by:

- Morphological characteristics using Gram's Stains

- Biological tests (catalase test $\left(\mathrm{H}_{2} \mathrm{O}_{2}\right)$, oxidase test, and mannitol salt agar).

A Statistical Analysis Using Statistical Package for social Science (SPSS) version 21. Descriptive statistics includes (percentage, median and mean rank) in tables. Inferential analysis which include statistical test of non-parametric data as Friedman and Mann Whitney U tests were used. 


\section{RESULTS}

Throughout all 8 visits a dramatic decrease in PLI and GI with highly significant changes during visits (Table 1).

Median of PLI changes from 1.280 at the first visit to 0.900 at the eight visit. While GI decrease from (1.595) at first visit to (1.045) at eight visit, which is the lowest score.

Table 2 shows the descriptive and statistical analysis of BOP changes throughout all visits.

Appears that a significant decrease of BOP median percentage during visits. The highest median in a first visit 59.990 decrease to 5.250 the lowest median of BOP at the last visit.

Results in table 3 illustrates the descriptive and statistical tests of both aerobic and anaerobic viable count (CFU $\backslash \mathrm{ml})$ in the examined medias. Although the mean of anaerobic viable count (24.337) is higher than that count of aerobic (10.158), but with statistically not significant difference between those counts $(\mathrm{P}>0.05)$.

The most common bacteria isolated from implant after 3 months in aerobic and anaerobic media were Streptococcus spp., Staphylococcus Aurous, G -ve diplococcus, G + ve Baclli and G ve Bcilli., their percentage under aerobic condition were $50 \%, 36 \%, 8 \%, 3 \%$ and $3 \%$. While under Anaerobic condition were $30 \%$, $50 \%, 10 \%, 3 \%, 4 \%$. Also Entercoccus fecalis was cultured in anaerobic condition 3\% (Table 4).

Table 1: Descriptive and statistical test of Plaque index (PLI) and Gingival index (GI) change during visits.

\begin{tabular}{|c|c|c|c|c|c|c|}
\hline \multirow[b]{2}{*}{ Index } & \multirow[b]{2}{*}{ Visits } & \multirow[b]{2}{*}{ Median } & \multirow[b]{2}{*}{$\begin{array}{l}\text { Mean } \\
\text { Rank }\end{array}$} & \multicolumn{3}{|c|}{ Friedman test } \\
\hline & & & & $\begin{array}{c}\text { Chi- } \\
\text { square }\end{array}$ & $* \mathbf{d f}$ & $\begin{array}{c}\text { P- } \\
\text { value }\end{array}$ \\
\hline \multirow{8}{*}{ PLI } & 1 & 1.280 & 7.65 & \multirow{8}{*}{49.717} & \multirow{8}{*}{7} & \multirow{8}{*}{$\begin{array}{c}0.000 \\
\mathrm{HS}\end{array}$} \\
\hline & 2 & 1.020 & 6.00 & & & \\
\hline & 3 & 1.000 & 5.55 & & & \\
\hline & 4 & 1.000 & 4.55 & & & \\
\hline & 5 & 1.000 & 4.85 & & & \\
\hline & 6 & .900 & 2.45 & & & \\
\hline & 7 & .900 & 2.85 & & & \\
\hline & 8 & .900 & 2.10 & & & \\
\hline \multirow{8}{*}{ GI } & 1 & 1.595 & 7.50 & \multirow{8}{*}{36.926} & \multirow{8}{*}{7} & \multirow{8}{*}{$\begin{array}{c}0.000 \\
\mathrm{HS}\end{array}$} \\
\hline & 2 & 1.370 & 6.00 & & & \\
\hline & 3 & 1.240 & 5.50 & & & \\
\hline & 4 & 1.165 & 4.65 & & & \\
\hline & 5 & 1.095 & 3.35 & & & \\
\hline & 6 & 1.090 & 3.95 & & & \\
\hline & 7 & 1.055 & 2.70 & & & \\
\hline & 8 & 1.045 & 2.35 & & & \\
\hline
\end{tabular}

$\mathrm{HS}=$ highly significant at $\mathrm{P}<0.01 . * \mathrm{df}=$ degree of freedom
Table 2: Descriptive and statistical test of median percentage of surfaces with bleeding on probing (BOP) score 1 change during visits.

\begin{tabular}{|c|c|c|c|c|c|}
\hline \multirow{2}{*}{ Visits } & \multirow{2}{*}{ Median } & \multirow{2}{*}{$\begin{array}{c}\text { Mean } \\
\text { Rank }\end{array}$} & $\begin{array}{c}\text { Friedman test } \\
\text { Cquare }\end{array}$ & df & $\begin{array}{c}\text { P- } \\
\text { value }\end{array}$ \\
\hline 1 & 59.990 & 7.90 & & & \\
\hline 2 & 37.900 & 6.55 & & & \\
\hline 3 & 25.000 & 6.20 & & & \\
\hline 4 & 16.540 & 5.20 & \multirow{2}{*}{65.734} & 7 & $\begin{array}{c}0.000 \\
\text { HS }\end{array}$ \\
\hline 5 & 10.200 & 3.95 & & & \\
\hline 6 & 8.300 & 3.00 & & & \\
\hline 7 & 6.100 & 1.80 & & & \\
\hline 8 & 5.250 & 1.40 & & & \\
\hline \multicolumn{5}{|c|}{ HS=highly significant at $\mathrm{P}<0.01}$. \\
\hline
\end{tabular}

Table 3: Descriptive and statistical test of viable count between aerobic and anaerobic bacteria after 3 months of insertion $20 \mathrm{DI}$.

\begin{tabular}{|c|c|c|c|l|}
\hline Descriptive & \multicolumn{2}{|c|}{ Bacterial Groups } & Z & P-value \\
\cline { 2 - 3 } statistics & Aerobic & Anaerobic & & \\
\hline Minimum & 1.040 & 1.100 & & \\
\hline Maximum & 51.000 & 98.000 & \multirow{2}{*}{0.685} & $\begin{array}{l}0.512 \\
* \mathrm{NS}\end{array}$ \\
\hline Median & 3.250 & 7.000 & & \\
\hline Mean rank & 14.40 & 16.60 & & \\
\hline
\end{tabular}

$* \mathrm{NS}=$ non-significant at $\mathbf{P}>\mathbf{0 . 0 5}$

Table 4: The most common isolated aerobic and anaerobic bacteria in examined media / culture.

\begin{tabular}{|c|c|c|c|}
\hline \multicolumn{2}{|c|}{ Aerobic bacteria } & \multicolumn{2}{c|}{ Anaerobic bacteria } \\
\hline $\begin{array}{c}\text { Streptococcus Spp. } \\
\text { Staphylococcus } \\
\text { Aurous }\end{array}$ & $36 \%$ & $\begin{array}{c}\text { Streptococcus Spp. } \\
\text { Aurous }\end{array}$ & $30 \%$ \\
\hline G -ve diplococcus & $8 \%$ & $\mathrm{G}-$-ve diplococcus & $10 \%$ \\
\hline G +ve Bcilli & $3 \%$ & $\mathrm{G}+$ ve Bcilli & $3 \%$ \\
\hline $\mathrm{G}$-ve Bcilli & $3 \%$ & $\mathrm{G}-$ ve Bcilli & $4 \%$ \\
\hline & & $\begin{array}{c}\text { Enterococcus } \\
\text { fecalis }\end{array}$ & $3 \%$ \\
\hline
\end{tabular}

\section{DISCUSSION}

Implants inserted with the closed technique near half of it become contaminated during the surgical procedure ${ }^{(12)}$. After healing abutments placement, the microbial flora level extremely increases and most screw cavities are contaminated 6 weeks after they are exposed, suggesting that both surgery and microleakage contribute to the contamination.

As no statistical difference between aerobic and anaerobic culture was documented, the bacterial contamination is thought to be mostly facultative anaerobic. To identity the frequency of occurrence of gram negative $\mathrm{G}$-ve species, Gram staining was conducted on the cultured samples. 
Unexpectedly, samples presented the gram positive $G$ +ve coccoid species were the most common species (staphylococcous and Streptococcus). These species are the common initial colonizers belong to streptococcal species, for example Streptococcus gordonii and Streptococcus sanguinis.

Modern studies have also directed that in healthy implant sites, Gram-positive cocci have the greatest proportion of finding (13), which is corresponding with our results.

A studies has examined the bacterial species found in the biofilm present on the restorative components and in the internal parts of implants $(14,15)$. These studies indicated that these restorative components and internal parts were highly contaminated. All implants in the study were regarded to be free of peri-implantitis and radiographic estimation did not exhibit signs of significant bone loss beyond what is corresponding with crestal bone regeneration. Also the oral hygiene of the patient remain good and this help in maintaining the health of the periimplant tissue over the observative period.

Any bacteriological colonization should permanently be regarded a longstanding risk factor and should be removed.

\section{CONCLUSION}

We propose that prevention of implant screw hole contamination should be included in the standards of care in implant dentistry.

\section{REFERENCES}

1. Jung RE, Zembic A, Pjetursson BE, Zwahlen MS, Thoma D. Systematic review of the survival rate and the incidence of biological, technical, and aesthetic complications of single crowns on implants reported in longitudinal studies with a mean follow-up of 5 years. Clin Oral Implant Res. 2012;23(s6):2-1.

2. Askary AES. Reconstructive aesthetic implant surgegy. Wiley-Blackwell; 2003.
3. Dawson A, Chen S, Buser D, Cordaro L, Martin W, Belser U. The SAC classification in implant dentistry. Quintessenz Verlag; 2010.

4. Zwiad AA, Al-Nesairy AM, Ghanem NM. The influence of chlorhexidine mouthwash on oral microorganisms in existence of implant prosthesis. J Dent Impl. 2014;4(2):149.

5. Persson LG, Lekholm U, Leonhardt Å, Dahlen G, Lindhe J. Bacterial colonization on internal surfaces of Brånemark system ${ }^{\circledR}$ implant components. Clin Oral Impl Res. 1996;7(2):90-5.

6. Lang NP, Nyman SR. Supportive maintenance care for patients with implants and advanced restorative therapy. Periodontol 2000.1994;4(1):119-26.

7. Maffei G, Brouwer N, Dolman KM, van der Velden U, Roos D, Loos BG. Plasma levels of mannanbinding lectin in relation to periodontitis and smoking. J Periodontol. 2005; 76(11): 1881-9.

8. Silness J, Löe H. Periodontal disease in pregnancy II. Correlation between oral hygiene and periodontal condition. Acta Odontol Scand. 1964;22(1):121-35.

9. Löe H. The gingival index, the plaque index and the retention index systems. J Periodontol. 1967; 38(6 Part II):610-6.

10. Newbrun E. Indices to measure gingival bleeding. J Periodontol. 1996;67(6):555-61

11. Al-Mizraqchi A. Adherence of Mutans Streptococci on teeth surfaces: Microbiological and biochemical studies. Ph.D. Thesis, College of Science, University of Al-Mustansiriya, 1998.

12. Groenendijk E, Dominicus JJ, Moorer WR, Aartman IH. Microbiological and clinical effects of chlorhexidine enclosed in fixtures of 3I-Titamed ${ }^{\circledR}$ implants. Clin Oral Impl Res. 2004;15(2):174-9.

13. Shahabouee M, Rismanchian M, Yaghini J, Babashahi A, Badrian H, Goroohi H. Microflora around teeth and dental implants. Dent Res J. 2012; 9(2):215.

14. Cosyn J, Van Aelst L, Collaert B, Persson GR, De Bruyn $\mathrm{H}$. The peri-implant sulcus compared with internal implant and suprastructure components: a microbiological analysis. Clin Impl Dentist Relat Res. 2011;13(4):286-95

15. Do Nascimento C, Monesi N, Ito IY, Issa JP, de Albuquerque Junior RF. Bacterial diversity of periodontal and implant-related sites detected by the DNA checkerboard method. Eur J Clin Microbiol Inf Dis. 2011;30(12):1607-13.

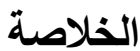

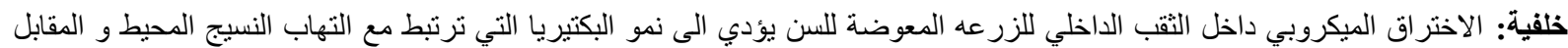

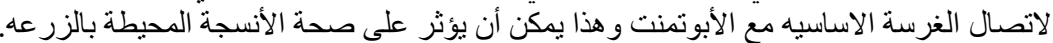

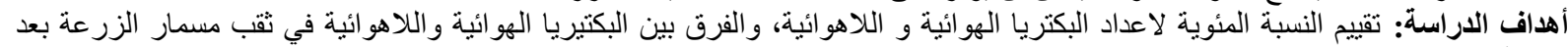

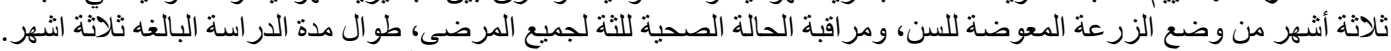

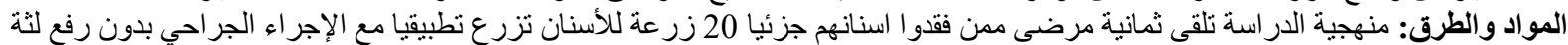

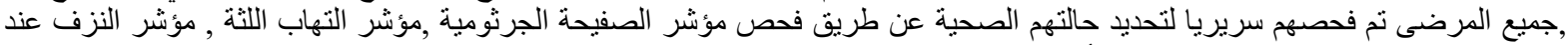
التسبيرومؤشر عمق الجيوب الخاص بهم كل أسبو عين طو ال فترة الدراسة.

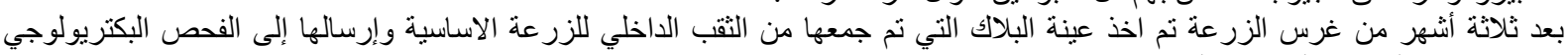

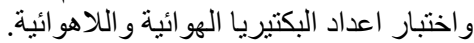

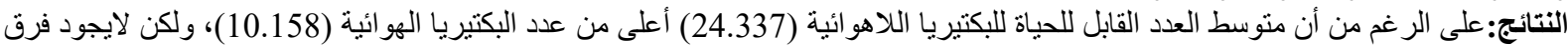
ذات دلالة إحصائية بين تللك التعدادات (P> (P) 0.05$).$ 